\title{
Correction to: Nano-Silicon Complexes Enhance Growth, Yield, Water Relations and Mineral Composition in Tanacetum parthenium under Water Deficit Stress
}

\author{
Shabnam Esmaili ${ }^{1}$ - Vahid Tavallali ${ }^{2} \cdot$ Bahram Amiri $^{3}$ \\ Published online: 8 November 2021 \\ (C) Springer Nature B.V. 2021
}

\section{Correction to: Silicon}

https://doi.org/10.1007/s12633-020-00605-Z

The original version of the article unfortunately contained an error.

A data was inadvertently added in the first and third author's affiliations. The correct authors' affiliations are shown below.

Publisher's Note Springer Nature remains neutral with regard to jurisdictional claims in published maps and institutional affiliations.

The online version of the original article can be found at https://doi.org/ 10.1007/s12633-020-00605-Z

Vahid Tavallali

vtavallali@gmail.com; v.tavalali@pnu.ac.ir

Shabnam Esmaili

Sh.es2@yahoo.com

Bahram Amiri

bchamiri@gmail.com

1 Ph.D. Student of Agronomy, Department of Agriculture, Firoozabad Branch, Islamic Azad University, Firoozabad, Iran

2 Department of Agriculture, Payame Noor University (PNU), Tehran, Iran

3 Department of Agriculture, Firoozabad Branch, Islamic Azad University, Firoozabad, Iran 